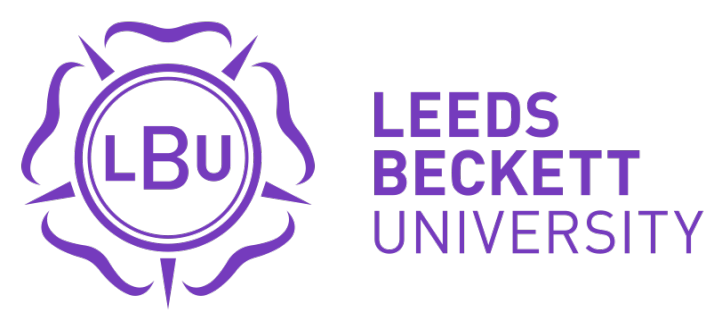

Citation:

Stanger, N and Backhouse, SH and Jennings, A and McKenna, J (2018) Linking motivational climate with moral behavior in youth sport : The role of social support, perspective taking and moral disengagement. Sport, Exercise, and Performance Psychology, 7 (4). pp. 392-407. ISSN 2157-3905 DOI: https://doi.org/10.1037/spy0000122

Link to Leeds Beckett Repository record:

https://eprints.leedsbeckett.ac.uk/id/eprint/4717/

Document Version:

Article (Accepted Version)

The aim of the Leeds Beckett Repository is to provide open access to our research, as required by funder policies and permitted by publishers and copyright law.

The Leeds Beckett repository holds a wide range of publications, each of which has been checked for copyright and the relevant embargo period has been applied by the Research Services team.

We operate on a standard take-down policy. If you are the author or publisher of an output and you would like it removed from the repository, please contact us and we will investigate on a case-by-case basis.

Each thesis in the repository has been cleared where necessary by the author for third party copyright. If you would like a thesis to be removed from the repository or believe there is an issue with copyright, please contact us on openaccess@leedsbeckett.ac.uk and we will investigate on a case-by-case basis. 
Linking motivational climate with moral behavior in youth sport: The role of social support, perspective taking and moral disengagement

Nicholas Stanger, Susan H Backhouse, Andrew Jennings, Jim McKenna Leeds Beckett University

Manuscript Accepted: 31 January, 2018

(C)American Psychological Association, 2018. This paper is not the copy of record and may not exactly replicate the final, authoritative version of the article. Please do not copy or cite without authors permission. The final article will be available, upon publication via its doi: $10.1037 /$ spy0000122 


\begin{abstract}
This study investigated whether motivational climate was associated with prosocial and antisocial behavior in youth athletes directly and indirectly via social support (i.e., emotional and esteem support), perspective taking, and moral disengagement. Two-hundred and seventyfive youth team sport players (156 boys; 119 girls) aged 11 to 16 years completed questionnaires assessing the study variables. Structural equation modelling revealed that mastery climate was positively associated with prosocial teammate behavior both directly and indirectly via social support. Mastery climate was also indirectly associated with prosocial opponent behavior via social support and perspective taking. Mastery climate was negatively associated with antisocial behavior towards opponents and teammates indirectly via social support, perspective taking, and moral disengagement. Performance climate was positively associated with antisocial behavior towards teammates directly and indirectly via moral disengagement: It was also indirectly associated with antisocial behavior towards opponents via moral disengagement. Our findings extend understanding about the variables that might explain relationships between motivational climate and moral conduct in youth athletes. Implications for sport practitioners are considered, especially in relation to approaches that could help foster moral character in young people through sport.
\end{abstract}

Key words: antisocial behavior, mastery climate, morality, performance climate, prosocial behavior. 
Linking motivational climate with moral behavior in youth sport: The role of social support, perspective taking and moral disengagement

For some time, it has been suggested that sport provides an avenue for young people to learn and develop a range of positive psychosocial and behavioral outcomes, such as moral character, which is reflected in values such as being respectful and honest (e.g., Weiss, 2008; Holt et al., 2016). However, the competitive nature of sport can potentially result in learning and engaging in negative social behaviors that can have adverse consequences on others' welfare (e.g., Bredemeier \& Shields, 1986). Given that sport does not automatically build moral character, identifying how the social environment is linked with behaviors that may reflect moral character in young people is a significant research endeavor (e.g., Weiss, 2008). In this research, we sought to enhance our understanding about the relationship between social variables and moral behavior of young athletes, and examine variables that might explain these relationships.

\section{Moral Behavior in Sport}

As a social context, sport provides ample opportunities to engage in moral behaviors that can have implications for the welfare of others (Kavussanu, 2008). For instance, athletes can engage in prosocial behaviors, which are actions intended to help or benefit another (Eisenberg \& Fabes, 1998), such as helping an opponent back to their feet, or congratulating a teammate for good play. At the same time, athletes can behave antisocially by committing actions intended to harm or disadvantage another (Sage, Kavussanu, \& Duda, 2006), such as intentionally injuring an opponent or verbally abusing a teammate. Given the benefits of facilitating sport as an institution for positive psychosocial development, while also acknowledging the adverse consequences that antisocial behavior can have on the recipients (e.g., injury, distress), researchers have made considerable efforts to understand factors that are 
linked with morally relevant conduct in youth sport (e.g., Bolter \& Kipp, 2018; Bruner, Boardley, \& Côté, 2014; Kavussanu \& Spray, 2006).

Bandura's (1991) social cognitive theory of moral thought and action has guided many studies exploring moral behavior in sport. According to Bandura, individuals exercise control over their behavior which is guided by moral standards learned through personal experiences and/or through socialisation processes, including modelling and interactions with others. In essence, the social environment can influence an individual's behavior and vice versa. These moral standards also regulate behavior through anticipated evaluative self-reactions whereby when individuals behave in line with their moral standards they can experience satisfaction, whereas engaging in behaviors that violate their moral standards can bring self-disapproval (e.g., guilt). Bandura (1999) also distinguished between two aspects of morality: proactive and inhibitive morality. Proactive morality refers to the power to behave humanely, while inhibitive morality is the power to refrain from behaving transgressively. Broadly, manifestations of proactive and inhibitive morality reflect prosocial and (lack of) antisocial behavior, respectively. Self-regulatory processes do not provide invariant control over moral conduct and there are several mechanisms by which self-regulatory processes can be disengaged; jointly denoted as moral disengagement (Bandura, 1991). Specifically, moral disengagement refers to eight psychosocial mechanisms or processes that justify antisocial behavior, place responsibility or blame onto others, or downplay the consequences of transgressive conduct which can reduce or eliminate the perpetrator experiencing the typical negative self-evaluative emotional consequences (e.g., guilt). These mechanisms or processes are: moral justification; euphemistic labelling; advantageous comparison; diffusion of responsibility; displacement of responsibility; minimizing, distorting, or ignoring consequences; dehumanization; and attribution of blame. Research indicates that moral disengagement is a moderate-to-strong positive predictor of antisocial behavior (e.g., Boardley \& Kavussanu, 2009; Stanger, Kavussanu, Boardley, \& Ring, 
2013), and is either negligibly or weakly (negatively) associated with prosocial behavior, in sport (Hodge \& Lonsdale, 2011; Kavussanu, Stanger, \& Boardley, 2013).

Researchers have also investigated the potential indirect role of moral disengagement on the relationship between a range of constructs and moral behavior, including achievement goal orientation (Boardley \& Kavussanu, 2010), controlled motivation (Hodge \& Lonsdale, 2011), and character-building competency (Boardley \& Kavussanu, 2009). However, research has yet to consider the potential indirect relationships between social variables and moral behavior via moral disengagement in youth athletes. Given the role significant others can have on adolescent athletes’ psychosocial development (e.g., Fraser-Thomas, Côté, \& Deakin, 2005), and research indicates that coaches and teammates could influence the use of moral disengagement to justify antisocial actions (e.g., Traclet, Romand, Moret, \& Kavussanu, 2011), such research would provide further insight for tailored interventions in this population.

\section{Motivational Climate}

One social variable associated with moral behavior in sport is coach created motivational climate (e.g., Bortoli, Messina, Zorba, \& Robazza, 2012). Motivational climate reflects the achievement goals athletes perceive are being promoted within a particular context. Two types of motivational climate have been described: mastery and performance climate (Ames, 1992). Mastery climate emphasises success and achievement based on self-referenced criteria, such as skill mastery and improvement. Performance climate reflects an environment where success and achievement are based on other referenced criteria such as outperforming, or being superior over, others.

Mastery and performance climate have been differentially associated with distinct moral behaviors (see Kavussanu \& Stanger, 2017). For instance, mastery climate has been positively associated with prosocial behavior and negatively associated with antisocial behavior (e.g., Boardley \& Kavussanu, 2009; Bortoli et al., 2012), with these relationships being more salient 
for behavior directed towards teammates than opponents (Boardley \& Kavussanu, 2009). In contrast, performance climate has been positively associated with antisocial behavior (e.g., Bortoli et al., 2012; Sage \& Kavussanu, 2008), with such relationships being more salient for behavior directed towards teammates than opponents (Boardley \& Kavussanu, 2009), and either weakly or negligibly associated with prosocial behavior (Boardley \& Kavussanu, 2009; Sage \& Kavussanu, 2008).

Moral disengagement offers one potential mechanism to explain the relationship between motivational climate and antisocial behavior. A performance climate may encourage players to engage in antisocial conduct to reach normative based goals (Ames, 1992; Kavussanu \& Spray, 2006) via employing moral disengagement. In a performance climate, where normative success is highly valued, athletes could be inclined to use moral justification, which refers to portraying harmful conduct as having a valued moral or social purpose, by justifying antisocial conduct towards an opponent to have a social function to help facilitate their team winning. In contrast, in a mastery climate, individuals may be less likely to justify or engage in antisocial behavior because doing so would not be a 'true' test of competence (e.g., Duda, Olsen \& Templin, 1991). Indeed, research has revealed that performance climate is positively, and mastery climate is negatively, associated with moral disengagement (e.g., Boardley \& Kavussanu, 2009). However, research has yet to confirm whether motivational climate is indirectly linked with prosocial and antisocial behavior via moral disengagement, or tested for social variables that may explain these relationships.

\section{Social Support}

Social support, which involves 'an exchange of resources between at least two individuals perceived by the provider or recipient to be intended to enhance the well-being of the recipient' (Schumaker \& Brownell, 1984, p.13), is a social variable that has been neglected in the context of moral behavior in sport. Scholars increasingly differentiate received support and perceived 
support; perceived support has been most closely associated with positive outcomes (Haber, Cohen, Lucas, \& Baltes, 2007). Perceived available support refers to one's judgments of having the potential for, and timely access to, support from peers, family, coaches and teammates when such assistance is needed (e.g., Freeman, Coffee, \& Rees, 2011). Social support comprises four dimensions: emotional, esteem, informational, and tangible support (Cutrona \& Russell, 1990). In this research, we focus on emotional and esteem support because they reflect affective aspects of support that most closely align to supporting others' well-being. Emotional support refers to others being available and willing to provide comfort and care. Esteem support refers to others bolstering a sense of belief and competence (Cutrona \& Russell, 1990).

Social support may promote prosocial behavior through reciprocation. In a social environment when an individual perceives being supported and cared for, this may represent a context where positive social behaviors are expressed and thereby become reciprocated (e.g., de Guzman, Jung, \& Ahn Do, 2012). In adolescents, social support positively predicted prosocial behaviors, particularly altruistic behaviors which are motivated purely to benefit others (de Guzman et al., 2012). Though prosocial behavior may not always be altruistic, and could be motivated by other factors such as conforming to perceived social conventions or to be viewed favorably in public (e.g., Eisenberg, Eggum, \& Di Giunta, 2010), these findings suggest that social support may be associated with prosocial behavior in sport. Indeed, research has revealed that relational coach support (which comprised emotional support) positively predicted youth athletes' on-field prosocial behavior (e.g., Rutten et al., 2008).

Athletes may be more likely to perceive social support in a mastery climate where focus is on individual development and effort is praised and rewarded, than in a context where normative comparisons are made and mistakes generate anxiety (e.g., Duda \& Ntoumanis, 2005). Given that cooperation, encouragement and supporting teammates characterizes the mastery climate (Ames, 1992), this may enhance perceptions of feeling cared for (emotional 
support), and encouraged (esteem support). Indeed, mastery climate has been positively associated with social support (Alfermann, Lee, \& Wurth, 2005), and perceived teacher support in physical education settings (Cox \& Williams, 2008). However, the role of social support on the relationship between mastery climate and moral conduct has yet to be examined in sport. Given previous findings, relationships between motivational climate, particularly mastery climate, and prosocial behavior, may be indirectly related via emotional and esteem support.

\section{Perspective Taking}

Although social support could be associated with prosocial behavior via reciprocation, this relationship may also be explained by social support promoting personal competencies that underpin prosocial tendencies (de Guzman et al., 2012). One potential personal competency associated with prosocial (and deterring antisocial) behavior is perspective taking (e.g., de Guzman et al., 2012). Perspective taking refers to the tendency to spontaneously adopt the psychological point of view of others (Davis, 1983). Adolescents can employ perspective taking (e.g., de Guzman et al., 2012; Hawk et al., 2013), and perspective taking has been positively associated with prosocial behavior in adolescents (e.g., Eisenberg, Zhou, \& Koller, 2001; de Guzman et al., 2012).

Social support may promote perspective taking. Specifically, in an environment where one feels supported and cared for, they are likely recipients of others being receptive to their needs and situation, and thereby may be more willing to adopt the perspective of others. Indeed, research has revealed that social support is indirectly associated with prosocial behavior via being positively associated with perspective taking in adolescents (de Guzman et al., 2012). Therefore, it is possible that perspective taking may contribute to explaining the relationship between social support and moral behaviors in sport.

Research has also revealed that perspective taking is negatively associated with antisocial behavior in sport in cross sectional studies (e.g., Stanger, Kavussanu, \& Ring, 2017), 
while experimental studies have demonstrated that inducing perspective taking reduces athletes' aggression (Stanger, Kavussanu, McIntyre, \& Ring, 2016) and reported likelihood to aggress (Stanger, Kavussanu, \& Ring, 2012). Reduced moral disengagement offers a potential mechanism to explain the link between perspective taking and lower antisocial behavior. Perspective taking may facilitate the humanization of others and awareness of the potential distress antisocial conduct can inflict on others (e.g., Bandura, 1999), and thereby make individuals less likely to distort the consequences of their actions or attribute blame to, or dehumanize, potential victims (e.g., Detert, Treviño, \& Sweitzer, 2008). Indeed, perspective taking has been negatively associated with moral disengagement in sport (Shields, Funk, \& Bredemeier, 2015). However, research has yet to examine whether perspective taking and antisocial behavior in sport are associated indirectly via moral disengagement.

\section{The Present Study}

Research confirms that motivational climate is associated with moral conduct in sport. However, research has yet to test whether motivational climate and moral behavior in sport are indirectly related via social support, perspective taking and moral disengagement. This study aimed to address these issues. Specifically, we examined whether mastery climate was positively associated with prosocial behavior directly and indirectly via social support (e.g., Alfermann et al., 2005), and in turn, perspective taking (e.g., de Guzman et al., 2012). We also investigated whether mastery climate was negatively associated with antisocial behavior (e.g., Bortoli et al., 2012) directly and indirectly via social support, and in turn, via perspective taking being negatively associated with moral disengagement (e.g., Shields et al., 2015). Lastly, we examined whether performance climate was positively associated with antisocial behavior directly and indirectly via moral disengagement. The hypothesized model is presented in Figure 1.

\section{Method}

\section{Participants}


SOCIAL VARIABLES, PERSPECTIVE TAKING AND MORAL BEHAVIOR

Participants were 275 youth team sport players (156 boys and 119 girls), who were aged $11-16$ years $(M=13.69 ; S D=1.90)$ and recruited through schools in the United Kingdom. They competed in soccer $(n=134)$, netball $(n=54)$, rugby $(n=45)$, field hockey $(n=32)$, basketball $(n=8)$ and American football $(n=2)$. Participants competed in their respective sports at international/ national (13\%), regional/ county (33\%) and club or school (54\%) levels for an average of $5.39(S D=3.17)$ years.

\section{Measures}

Prosocial and antisocial behavior. The 20-item Prosocial and Antisocial Behavior in Sport Scale (PABSS; Kavussanu \& Boardley, 2009) was used to measure prosocial and antisocial behavior towards both teammates and opponents in sport. Specifically, the PABSS comprises of four subscales that measure: antisocial behavior towards opponents (eight items; e.g., tried to injure an opponent) and teammates (five items; e.g., swore at a teammate) as well as prosocial behavior towards opponents (three items; helped an opponent off the floor) and teammates (four items; e.g., encouraged a teammate). Participants were asked how often they engaged in each behavior during the past 12 months whilst competing in their main sport on a 5-point Likert type scale anchored by 1 (never) to 5 (very often).

Similar to previous research using the PABSS in youth athletes (e.g., Bolter \& Kipp, 2018), eight items were very slightly reworded to facilitate comprehension for the youth athletes by using synonyms for some words. Specifically, we changed "deliberately" and "intentionally" to "on purpose" or "aimed", "retaliated" to "hit back", "congratulated" to "praised", "positive feedback" to "positive comments", "showed frustration" to "got angry", and "physically intimidated" to "bullied". For instance, the item "congratulated a teammate for good play" changed to "praised a teammate for good play". Research has supported the validity of the PABSS, while also demonstrating that all subscales possess good to very good internal consistency ( $\alpha$ 's .73 to .86) (Kavussanu \& Boardley, 2009; Kavussanu et al., 2013). 
Perceived motivational climate. The 12-item Motivational Climate Scale for Youth Sports (Smith, Cumming, \& Smoll, 2008) was used to measure players' perceptions of coaches/ PE teacher initiated motivational climate. Specifically, players were asked to consider the coach or physical education teacher who plays the biggest role in their sport participation and then complete each item by thinking specifically about this coach/ PE teacher. These instructions were followed by two 6-item subscales measuring mastery (e.g., "the coach/PE teacher tells us that trying our best is the most important thing") and performance (e.g., "the coach/ PE teacher spends less time with the players who are not as good") climate. Participants responded to each item on a 5-point Likert type scale anchored by 1 (not at all true) to 5 (extremely true). This measure has received psychometric support in youth sport players (aged between 9 to 14 years) with alpha coefficients ranging from .78 to .84 for mastery climate, and .74 to .75 for performance climate (Smith et al., 2008).

Social support. Emotional and esteem support was measured using the Perceived Available Support in Sport Questionnaire (Freeman et al., 2011). The stem "When playing your main sport, if needed to what extent would those around you ..." was followed by two 4-item subscales measuring emotional support (e.g., "always be there for you), and esteem support (e.g., boost your self-belief). Participants responded to each item on a 5-point Likert type scale anchored by 1 (not at all) to 5 (extremely so). Psychometric support for the scales have been provided with alpha coefficients of .87 (emotional support) and .83 (esteem support) for the separate scales, while support has also been provided for combining them (Freeman et al., 2011).

Perspective taking. Perspective taking was measured using the 7 -item perspective taking subscale from the Interpersonal Reactivity Index (IRI; Davis, 1983). Participants were asked to what extent each item (e.g., "when I'm upset at someone I usually try to put myself in his/her shoes for a while") described them, and responded on a Likert type scale anchored by 1 (does not describe me at all) to 5 (describes me greatly). The IRI has received support for its 
psychometric properties with alpha coefficients ranging from .71 to .77 (Davis, 1983) including in adolescents (e.g., Hawk et al., 2013), and been applied to samples from aged 11 years in previous research (e.g., de Guzman et al., 2012; Overgaauw et al., 2017).

Moral disengagement. Moral disengagement in sport was measured using the 8-item Moral Disengagement in Sport Scale - short (Boardley \& Kavussanu, 2008). Participants were asked to rate their level of agreement to each item (e.g., "bending the rules is a way of evening things up") on a 7-point Likert type scale, anchored by 1 (strongly disagree) to 7 (strongly agree). Psychometric support for the scale has been provided with alpha coefficients ranging from .80 to .85 (Boardley \& Kavussanu, 2008).

\section{Procedure}

The project was approved by the university ethics committee prior to data collection. All data collection took place at the participant's school during school time at least 3 months into the typical competitive season or school term to allow sufficient time for participants to be embedded into the environment (i.e., from December to May). As participants were aged 16 years and younger, headteacher and parental consent was secured for each participant. Participants were then invited to take part in the study at a convenient time (e.g., during registration). Participants were clearly notified verbally and via an information sheet about the purpose of the study and the voluntary nature of participation, were reassured that responses would be kept confidential, that questionnaires were completed anonymously, and reminded about their right to withdraw from the study. Participants who completed a consent form were then provided with the questionnaire pack comprising the measures described above. To check for suitable comprehension, the initial 15 participants (all aged 11-12 years) were asked to complete the questionnaire and note any questions they found difficult to read or understand, and inform the researcher; no issues were reported. Moreover, a researcher/ research assistant was available should any participant require any clarification on the wording of items. Once 
SOCIAL VARIABLES, PERSPECTIVE TAKING AND MORAL BEHAVIOR

completed, participants sealed their questionnaire into an envelope and returned it directly back to a researcher. Participants were then thanked for their participation and debriefed.

\section{Data Analysis}

Data were first checked for normality and missing data. As the measures were undertaken on a youth population, the factorial validity of each measure was then assessed through Confirmatory Factor Analysis (CFA) using the maximum likelihood estimation via Stata v14. Factor loadings for each item and residual errors were checked and the model fit was tested for each measure using the chi-square test, the comparative fit index (CFI), the Tucker-Lewis index (TLI), and the root mean square error of approximation (RMSEA) and standardised root mean squared residual (SRMR). Conventional criteria (Marsh, Hau, \& Wen, 2004) were used to assist with model assessment whereby values of $\chi^{2 / / d f}<.3$, CFI and TLI $>.90$, and RMSEA and SRMR $\leq .10$, were considered to reflect adequate model fit, whereas $\chi^{2 /} / \mathrm{df}<.2$, CFI and TLI $>$ .95 , and RMSEA and SRMR $\leq .06$, were considered to present excellent model fit.

We then tested the overall measurement model which included all latent factors (Anderson \& Gerbing, 1988). The structural model and tests for indirect effects were then conducted using structural equation modelling (Anderson \& Gerbing, 1988). To test for indirect effects, we employed bootstrapping which is considered one of the most powerful methods when testing for indirect effects (e.g., Shrout \& Bolger, 2002) using AMOS version 22. The model was run with 5,000 bootstrap samples to calculate the estimate of the indirect effect and 95\% confidence intervals (CIs). When the CI does not cross zero there is evidence of an indirect effect.

\section{Results}

\section{Preliminary Analysis}

Only $0.73 \%$ of the data were missing with no apparent pattern to these cases. Five participants were removed as they missed out at least one subscale (or section). A number of 
other participants $(n=48)$ had a small amount of missing data (i.e., maximum of two items across different scales) and these values were replaced using the mean of the non-missing items for the respective subscale in each individual case (Graham, Cumsille, \& Elek-Fisk, 2003). Data screening revealed no extreme outliers, and univariate skewness and kurtosis values indicated no significant deviation from normality. However, indices of multivariate nonnormality were substantial, so we employed Satorra-Bentler (S-B) $\chi^{2}$ and associated robust model fit indices in all models using Stata v14.

\section{Confirmatory Factor Analyses and Correlations.}

The CFA on the 2-factor model for motivational climate revealed one performance climate item ("the coach/PE teacher tells us to try to be better than our teammates") possessed a low factor loading of .23, and another item possessed high residual error ("winning games is the most important thing for the coach/ PE teacher"), so were removed. The subsequent model reflected an excellent fit, S-B $\chi^{2}(34)=44.43, p=.11 ; \chi^{2 /} / \mathrm{df}=1.31, \mathrm{RMSEA}=.03, \mathrm{CFI}=.99$, $\mathrm{TLI}=.98, \mathrm{SRMR}=.04$. The 2-factor model for emotional support and esteem support represented an adequate fit to the data, $\mathrm{S}-\mathrm{B} \chi^{2}(19)=53.38, p<.001 ; \chi^{2 /} / \mathrm{df}=2.81, \mathrm{RMSEA}=$ $.08, \mathrm{CFI}=.97, \mathrm{TLI}=.95, \mathrm{SRMR}=.03$. Investigation of residuals and modification indices from the Lagrange multiplier test revealed correlations for items across subscales. As these two factors were very highly correlated $(r=.83, p<.001)$, we opted for a single factor model comprising of both emotional and esteem support. Due to the presence of high correlated errors between three pairs of items, we specified these in the model resulting in an excellent model fit, $\mathrm{S}-\mathrm{B} \chi^{2}(17)=33.90, p=.01 ; \chi^{2 /} / \mathrm{df}=1.99, \mathrm{RMSEA}=.06, \mathrm{CFI}=.99, \mathrm{TLI}=.98, \mathrm{SRMR}=.03$. This one factor solution was used in subsequent analyses. As self-esteem can entail an emotional evaluation of oneself and one's abilities (e.g., Brown, Dutton, \& Cook, 2001), we loosely label this amalgamation of the two subscales as affective social support. 
For the perspective taking scale, similar to some previous research with adolescents (e.g., Eisenberg et al., 2001) the two reversed scored items had low factor loadings of below .24, and were removed. The subsequent 5-item model demonstrated an adequate fit, $\mathrm{S}-\mathrm{B} \chi^{2}(5) 12.64, p$ $=.03 ; \chi^{2 /} / \mathrm{df}=2.53, \mathrm{RMSEA}=.08, \mathrm{CFI}=.98, \mathrm{TLI}=.96, \mathrm{SRMR}=.03$. For moral disengagement, one item was removed ("it is unfair to blame players who only play a small part in unfair play used by their team") due to a low factor loading of .23, and we also specified for a correlated error between two pairs of items. The subsequent 7-item model demonstrated an excellent model fit, $\mathrm{S}-\mathrm{B} \chi^{2}(12)=11.41, p=.49 ; \chi^{2 /} / \mathrm{df}=0.95, \mathrm{RMSEA}=.04, \mathrm{CFI}=1.00, \mathrm{TLI}=$ $1.00, \mathrm{SRMR}=.03$. For the PABSS, we removed one item with high residual error ("broke the rules of the game on purpose") and correlated errors between four pairs of items for the antisocial opponent behavior subscale, as well as correlated the errors between one pair of items for the antisocial teammate behavior subscale. The subsequent model revealed an excellent model fit for the 4-factor model, S-B $\chi^{2}(142)=243.87, p<.001 ; \chi^{2 /} / \mathrm{df}=1.72, \mathrm{RMSEA}=.05$, $\mathrm{CFI}=.96, \mathrm{TLI}=.95, \mathrm{SRMR}=.05$.

The full measurement model which comprised of all 49 remaining items represented an adequate fit, $\mathrm{S}-\mathrm{B} \chi^{2}(1082)=1529.87, p<.001 ; \chi^{2 /} / \mathrm{df}=1.41, \mathrm{RMSEA}=.04, \mathrm{CFI}=.94, \mathrm{TLI}=$ $.93, \mathrm{SRMR}=.06$. Based on remaining items for each subscale, the descriptive statistics, alpha coefficients and correlations are reported in Table 1; alpha coefficients indicated that the internal consistency were adequate to excellent (e.g., Kline, 2016) for all variables.

\section{Main Analyses}

The main purpose of this study was to examine our hypothesized model (Figure 1), which represented an adequate fit to the data (see Table 2). Due to the deviations in multivariate normality, bootstrapping was employed to provide a robust assessment of parameter estimates for each path in the model. No direct relationships were noted for paths between perspective taking and prosocial teammate behavior (standardized estimate $=-.01, p=.94$ ), mastery climate 
and moral disengagement (standardized estimate $=-.06, p=.56$ ), or moral disengagement with prosocial teammate $($ standardized estimate $=-.00, p=.97$ ) and prosocial opponent (standardized estimate $=-.04, p=.63$ ) behavior. Therefore, we ran a more parsimonious model without these paths. This revised (and final) model possessed an adequate, and slightly improved, model fit $\left(\Delta \chi^{2 /} / \mathrm{df}=-0.01 ; \Delta \mathrm{CFI}=+.001 ; \Delta \mathrm{TLI}=+.001\right)$. Regarding variance, the model accounted for $37 \%$ of prosocial teammate behavior, $15 \%$ of prosocial opponent behavior, $45 \%$ of antisocial teammate behavior, and $55 \%$ of antisocial opponent behavior. Bootstrap parameter estimates for the paths in the final model are presented in Figure 2. Mastery climate had a direct positive relationship with prosocial teammate behavior and affective social support, but not with prosocial opponent behavior. Affective social support was directly and positively associated with prosocial behavior towards both teammates and opponents, and perspective taking. Perspective taking had a direct positive association with prosocial opponent behavior, and a direct negative relationship with moral disengagement and antisocial behavior towards teammates, but did not have a significant link with antisocial behavior towards opponents. Performance climate had a direct positive relationship with moral disengagement and antisocial teammate behavior, but not with antisocial opponent behavior. Moral disengagement was directly and positively associated with antisocial behavior towards teammates and opponents.

The results for the testing of indirect effects are presented in Table 3. All indirect effects in the model were statistically significant. Specifically, the results revealed that mastery climate was indirectly associated with prosocial behavior towards teammates via affective social support. In addition, the indirect path for the relationship between mastery climate and prosocial behavior towards opponents via affective social support, and in turn, perspective taking was significant. Social support was also indirectly linked with prosocial opponent behavior via perspective taking. Mastery climate was indirectly associated with antisocial 
behavior towards teammates and opponents via affective social support, perspective taking, and moral disengagement. Perspective taking and performance climate were indirectly linked with antisocial behavior towards teammates and opponents via moral disengagement.

Additional model testing. To verify our model, we tested some alternative models. First, we tested a model where perspective taking was included as an independent (exogenous) variable. Specifically, the model presented in Figure 2 was re-specified so there was no path between social support and perspective taking, and perspective taking had a bidirectional correlation with mastery climate and performance climate. This model had a slightly weaker model fit than our final model $\left(\Delta \chi^{2 /} / \mathrm{df}=+0.01 ; \Delta \mathrm{CFI}=-.001 ; \Delta \mathrm{TLI}=-.001 ; \Delta \mathrm{SRMR}=+.002\right)$. We also tested a saturated model whereby all possible pathways between latent variables were included to check no significant paths were missing from our model (e.g., Anderson \& Gerbing, 1988; Gefen, Rigdon, \& Straub, 2011). Specifically, in the saturated model both exogenous variables (i.e., mastery climate and performance climate) were linked with all endogenous variables with pathways adjoining endogenous variables in the hypothesized direction (e.g., social support with perspective taking and moral disengagement). Also, all endogenous and exogenous variables were linked with prosocial and antisocial behavior towards teammate and opponents, and bidirectional pathways were specified between all prosocial and antisocial behaviors as well as between mastery climate and performance climate. This saturated model had a marginally weaker fit on some indices $\left(\Delta \chi^{2 / / d f}=+0.01 ; \Delta \mathrm{CFI}=-.002 ; \Delta \mathrm{TLI}=-.003\right)$, though did have a lower SRMR $(\triangle \mathrm{SRMR}=-.003)$. However, no new direct or indirect effects were found.

Given that perspective taking may differ with age (e.g., Hawk et al., 2013), we tested each model controlling for age. The respective model fits are presented in Table 2. Similar to the original model testing, the best model fit was revealed for the final (parsimonious) model. Moreover, all significant direct $(\Delta$ standardised estimate $=\leq \pm .04)$ and indirect $(\Delta$ standardized 
SOCIAL VARIABLES, PERSPECTIVE TAKING AND MORAL BEHAVIOR

estimate $\leq \pm .06)$ associations remained as per the original model testing. Similarly, no new significant direct or indirect effects were found in the saturated model.

\section{Discussion}

To address gaps in understanding regarding how social variables are associated with moral behavior in youth athletes, this study investigated direct and indirect associations between motivational climate and prosocial and antisocial behavior in young athletes, via social support and perspective taking for prosocial behavior, as well as moral disengagement for antisocial behavior. Our findings provide new insights into how motivational climate is associated with moral behavior in youth athletes and draw attention to the variables that may account for these relationships.

\section{Predictors of Prosocial Behavior}

Mastery climate was directly and positively associated with reported prosocial behavior towards teammates, but not towards opponents. These findings align with previous research demonstrating the links between mastery climate and prosocial behavior towards teammates are stronger than towards opponents (Boardley \& Kavussanu, 2009). Mastery climate reflects a team environment, potentially making it more likely to play a larger role in intra-team functioning and behavior (e.g., Boardley \& Kavussanu, 2009). Mastery climate was indirectly associated with prosocial teammate behavior via being positively associated with affective social support, and indirectly associated with prosocial opponent behavior via affective social support, and in turn, perspective taking. These findings support previous research highlighting positive associations between mastery climate and social support in sport (Alfermann et al., 2005) and support from Physical Education teachers (Cox \& Williams, 2008) as well as between social support and dimensions of prosocial behavior in adolescents (e.g., de Guzman et al., 2012).

Although perspective taking was positively associated with both prosocial behavior towards teammates and opponents in correlational analysis, it was only positively associated with 
prosocial behavior towards opponents in the model. This finding corroborates previous research showing that empathy (established by combining scales for perspective taking and empathic concern) is more strongly associated with prosocial opponent, than prosocial teammate, behavior (Kavussanu \& Boardley, 2009; Kavussanu et al., 2013). In the sporting context, individuals who adopt higher levels of perspective taking may maintain moral reasoning that considers the welfare of opponents in a competitive context where they may be more inclined to focus on personal needs (e.g., Stanger et al., 2017; Bredemeier \& Shields, 1986).

Our findings seem to imply that affective social support may be directly associated with prosocial behavior towards teammates as a function of reciprocation. In contrast, as opponents are outside the athletes' immediate social network, reciprocation towards them may be less likely. Therefore, affective social support may be associated with prosocial behavior towards opponents (at least in part) through personal competencies expressed in social supportive environments, such as perspective taking (e.g., de Guzman et al., 2012). Also, consistent with previous research (e.g., Boardley \& Kavussanu, 2009), we identified no direct associations between performance climate and prosocial behavior. Other research has also shown null relationships between ego goal orientation and prosocial behavior (e.g., Kavussanu et al., 2013).

\section{Predictors Antisocial Behavior}

Mastery and performance climate were differentially associated with reported antisocial behavior. Mastery climate was negatively associated with antisocial behavior towards both teammates and opponents indirectly via affective social support, perspective taking, and in turn, moral disengagement. Moreover, consistent with research in both adult and youth athletes, performance climate was positively associated with antisocial behavior towards opponents (Boardley \& Kavussanu, 2009; Kavussanu, 2006; Sage \& Kavussanu, 2008) and teammates (Boardley \& Kavussanu, 2009). However, performance climate was only directly associated with antisocial behavior towards teammates in the model. These findings align with previous 
research showing that performance climate was more strongly predictive of antisocial teammate behavior, compared to opponent behavior (Boardley \& Kavussanu, 2009).

As expected, perspective taking was negatively associated with antisocial behavior. The direction of these findings are also consistent with previous studies (e.g., Stanger et al., 2017), including experimental studies manipulating perspective taking on aggression (Stanger et al., 2016) and likelihood to aggress in sport (Stanger et al., 2012). However, the direct association between perspective taking and antisocial opponent behavior was not significant. This may be attributable to the strength of the indirect effect via moral disengagement.

In support of theoretical predictions (Bandura, 1991) and previous research in sport (e.g., Boardley \& Kavussanu, 2009, 2010; Hodge \& Lonsdale, 2011; Kavussanu et al., 2013), moral disengagement was strongly and positively associated with antisocial behavior towards both teammates and opponents. Conversely, moral disengagement was negatively and only weakly associated with prosocial behavior. This finding is consistent with previous research (e.g., Boardley \& Kavussanu, 2009; Hodge \& Lonsdale, 2011 Kavussanu et al., 2013) and makes theoretical sense; moral disengagement refers to justifying antisocial behavior, rather than justifying not engaging in prosocial behavior.

A key finding from the current study is the indirect effect of moral disengagement on (i) the positive relationship between performance climate and antisocial behavior, and (ii) the negative association between perspective taking and antisocial behavior. Similar to previous studies, performance climate was positively (e.g., Boardley \& Kavussanu, 2009), and perspective taking (e.g., Shields et al., 2015) negatively, associated with moral disengagement. These findings indicate that higher levels of performance climate are associated with more antisocial behavior via being associated with higher inclinations towards employing mechanisms of moral disengagement. In addition, youth athletes who have a greater tendency to take the perspective of others may be more likely to consider the consequences, thereby reduce the justification, of antisocial behaviors 
on others. Our findings provide new concurrent evidence about how moral disengagement plays a distinctive role for how mastery climate, social support, perspective taking and performance climate are associated with antisocial behavior.

\section{Limitations and Future Research}

The findings feature a number of limitations. Cross-sectional research cannot infer the temporal direction of effects, so alternative sequencing of the model is possible (e.g., social support as a predictor of mastery climate rather than an outcome). It also limits the capacity to test mediation (e.g., Cole \& Maxwell, 2003). Though the sequencing of relationships shown here are based on strong theoretical and empirical foundations, deploying longitudinal designs would facilitate the testing of mediation. Also, further research developing and testing interventions targeted at moral behavior and psychosocial development on young people through sport is warranted. The current study justifies interventions featuring consideration of motivational climate, social support, perspective taking, and moral disengagement.

The present findings rely on self-report data. Future research could adopt a multi-measure approach by combining self-report with observational measures of moral conduct (e.g., Kavussanu, Stamp, Slade, \& Ring, 2009). Athletes were aged between 11-16 years, meaning that the findings can only be generalised to this age group. It should also be noted we adapted some items using synonyms to facilitate comprehension of questions within our sample; one item was not entirely equivalent to the original item in the PABSS whereby we changed "physically intimidated an opponent" to "bullied an opponent". Although our revised item comprised a high factor loading, it was the least frequent antisocial opponent behavior $(M=1.40, S D=0.91)$, suggesting it may be an uncommon behavior in youth sport. Future studies in youth athletes could consider employing the original item from the PABSS or a more equivalent behavior.

Although we recruited participants from schools who participated in a range of sports and likely competed in a range of different teams, it is possible that some players competed in 
the same team. As we did not capture the overlap of team membership to help maintain anonymity, we cannot be sure whether the data met the assumption of independence, leaving us unable to perform multi-level modelling analyses to address this issue. Researchers should consider approaches to allow for multilevel modelling when measuring group-level constructs such as motivational climate and social support in future studies (e.g., Papaionnou, Marsh, \& Theodorakis, 2004).

When measuring motivational climate, we contextualised questions to the coach or physical education teacher who plays the biggest role in the participants' sport participation. As participants completed other questions with reference to their main sport it was anticipated that participants were considering a coach/ teacher within their main sport. However, it is possible some players could have considered other coaches/ teachers outside their main sport. Lastly, we measured perspective taking without addressing other empathy components including empathic concern. Though perspective taking and empathic concern are discriminable factors (e.g., Davis, 1983), many studies have combined scales for these constructs to investigate the role of empathy on moral behavior in sport (e.g., Kavussanu \& Boardley, 2009; Kavussanu et al., 2013). Moreover, some scholars have argued that empathic concern can derive solely (or partly) from perspective taking (Eisenberg et al., 2010). Therefore, researchers could investigate whether empathic concern can contribute to the model, and potentially account (in part) for the links between perspective taking and moral behavior.

\section{Implications}

Based on the current findings, some applied implications are offered. First, youth sport coaches and teachers would do well to create a mastery climate where success is pursued by developing individual skill with emphasis being placed on commitment and effort, and trying to avoid a heavy focus on normative comparisons and winning. It appears youth sport programs as well as coach and teacher education may also benefit from targeting and developing 
perspective taking skills in youth athletes. Studies have shown that perspective taking can be enhanced in adolescents using appropriate training, including learning to identify affective states in others and role-playing (e.g., Pecukonis, 1990). Similar approaches could be employed using sporting situations and contexts. Our findings also highlight that adopting a mastery climate that is emotionally and esteem supportive could also promote perspective taking in young people. Finally, coaches and teachers should limit the likelihood of youth athletes justifying antisocial conduct through moral disengagement. To do so, care is needed to avoid over-emphasise on a performance climate, and aiming to promote a mastery climate, social support and perspective taking. Strategies promoting personal responsibility may also help to reduce youth athletes deploying justifications, such as displacement of responsibility and distortion of consequences that can facilitate antisocial conduct.

\section{Conclusion}

Identifying variables associated with prosocial and antisocial behavior in youth sport enhances the evidence base for promoting moral character of young people through sport. This study was the first to investigate how perspective taking and social support are associated with moral conduct in youth athletes as well as demonstrate the indirect paths via social support, perspective taking and moral disengagement on the relationship between motivational climate and both prosocial and antisocial behavior in sport. Future research could consider developing coach and teacher education programmes to target these variables and investigate their effectiveness in promoting prosocial, and deterring antisocial, behavior in youth sport. 


\section{References}

Alfermann, D., Lee, M. J., \& Würth, S. (2005). Perceived leadership behavior and motivational climate as antecedents of adolescent athletes' skill development. The Online Journal of Sport Psychology, 7, 14-36.

Ames, C. (1992). Achievement goals, motivational climate, and motivational processes. In G. C. Roberts, (Ed.), Motivation in sport and exercise (pp. 161-176). Champaign, IL: Human Kinetics.

Anderson, J. C., \& Gerbing, D. W. (1988). Structural equation modelling in practice: a review and recommended two-step approach. Psychological Bulletin, 103, 411-423.

Bandura, A. (1991). Social cognitive theory of moral thought and action. In W. M. Kurtines \& J. L. Gewirtz (Eds.), Handbook of moral behavior and development (pp. 45-103). Hillsdale, NJ: Erlbaum.

Bandura, A. (1999). Moral disengagement in the perpetration of inhumanities. Personality \& Social Psychology Review, 3, 193-209. doi:10.1207/s15327957pspr0303_3

Boardley, I. D. \& Kavussanu, M. (2008). The moral disengagement in sport scale - short. Journal of Sports Sciences, 26, 1507-1517. doi:10.1080/02640410802315054

Boardley, I. D., \& Kavussanu, M. (2009). The influence of social variables and moral disengagement on prosocial and antisocial behaviours in field hockey and netball. Journal of Sports Sciences, 27, 843-854. doi:10.1080/02640410902887283

Bolter, N. D., \& Kipp, L. E. (2018). Sportspersonship coaching behaviours, relatedness, and early adolescent athletes' prosocial and antisocial behaviour. International Journal of Sport \& Exercise Psychology, 16, 20-53. doi:10.1080/1612197X.2016.1142461

Bortoli, L., Messina, G., Zorba, M., \& Robazza, C. (2012). Contextual and individual differences on antisocial behaviour and psychobiosocial states in youth soccer players. Psychology of Sport \& Exercise, 13, 397-406. doi:10.1016/j.psychsport.2012.01.001

Bredemeier, B. J., \& Shields, D. L. (1986). Athletic aggression: An issue of contextual morality. Sociology of Sport Journal, 3, 15-28. doi:10.1123/ssj.3.1.15 
Brown, J. D., Dutton, K. A., \& Cook, K. E. (2001). From the top down: Self-esteem and selfevaluation. Cognition \& Emotion, 15, 615-631. doi:10.1080/02699930126063

Bruner, M. W., Boardley, I. D., \& Côté, J. (2014). Social identity and prosocial and antisocial behavior in youth sport. Psychology of Sport \& Exercise, 15, 56-64. doi:10.1016/j.psychsport/.2013.09.003

Cole, D. A., \& Maxwell, S. E. (2003). Testing mediational models with longitudinal data: Questions and tips in the use of structural equation modeling. Journal of Abnormal Psychology, 112, 23-44. doi:10.1037/0021-843X.112.4.558

Cox, A., \& Williams, L. (2008). The roles of perceived teacher support, motivational climate, and psychological need satisfaction in students' physical education motivation. Journal of Sport \& Exercise Psychology, 30, 222-239. doi:10.1123/jsep.30.2.222

Cutrona, C. E., \& Russell, D. W. (1990). Type of social support and specific stress: toward a theory of optimal matching. In B. R. Saraon, I. G. Sarason, \& G. R. Pierce (Eds.), Social support: An interactional view (pp. 319-366). New York: Wiley.

Davis, M. H. (1983). Measuring individual differences in empathy: Evidence for a multidimensional approach. Journal of Personality \& Social Psychology, 44, 113-126. doi:10.1037/00223514.44.1.113

Detert, J. R., \& Trevino, L. K., \& Sweitzer, V. L. (2008). Moral disengagement in ethical decision making: a study of antecedents and outcomes. Journal of Applied Psychology, 93, 374-391. doi:10.1037/0021-9010.93.2.374

Duda, J. L., \& Ntoumanis, N. (2005). After-school sport for children: Implications of a taskinvolving motivational climate. In J. L. Mahoney, R. W. Larson, \& J. S. Eccles (Eds.), Organized activities as contexts of development: Extracurricular activities, after school, and community programs (pp. 311-330). Mahwah, NJ: Erlbaum.

Duda, J. L., Olson, L. K., \& Templin, T. J. (1991). The relationship of task and ego orientation to sportsmanship attitudes and perceived legitimacy of injurious acts. Research Quarterly for Exercise \& Sport, 62, 79-87. doi:10.1080/02701367.1991.10607522 
Eisenberg, N., Eggum, N. D., Di Giunta, L. (2010). Empathy-related responding: Associations with prosocial behavior, aggression, and intergroup relations. Social Issues \& Policy Review, 4, 143-180. doi:10.1111/j.1751-2409.2010.01020.x.

Eisenberg, N., \& Fabes, R. A. (1998). Prosocial development. In N. Eisenberg (Ed.), Handbook of child psychology, Vol 3: Social, emotional, and personality development (pp. 701-778). New York: Wiley \& Sons Inc.

Eisenberg, N., Zhou, Q., \& Koller, S. (2001). Brazilian adolescents' prosocial judgment and behavior. Relations to sympathy, perspective taking, gender-role orientation, and demographic characteristics. Child Development, 72, 518-534. doi:10.1111/1467-8624.00294

Fraser-Thomas, J. L., Côté, J., \& Deakin, J. (2005). Youth sport programs: an avenue to foster positive youth development. Physical Education and Sport Pedagogy, 10, 19-40. doi:10.1080/17407898042000334890

Freeman, P., Coffee, P., \& Rees, T. (2011). The PASS-Q: the perceived available support in sport questionnaire. Journal of Sport \& Exercise Psychology, 33, 54-74. doi:10.1123/jsep.33.1.54

Gefen, D., Rigdon, E. E., \& Straub, D. (2011). An update and extension to SEM guidelines for administration and social science research. MIS Quarterly, 35 (2), iii-xiv.

Graham, J.W., Cumsille, P. E., \& Elek-Fisk, E. (2003). Methods for handling missing data. In J. A. Schinka, \& W.F. Velicer (Eds.), Handbook of Psychology (I. B Weiner, Editor), Vol 2, Research Methods in Psychology (pp.87-114). New York: Wiley.

de Guzman, M. R. T., Jung, E., \& Anh Do, K. (2012). Perceived social support networks and prosocial outcomes among Latino/a youth in the United States. International Journal of Psychology, 46, 413-424.

Haber, M., Cohen, J., Lucas, T., \& Baltes, B. (2007). The relationship between self-reported received and perceived social support. American Journal of Community Psychology, 39, 133-144. doi:10.1007/s10464-007-9100-9 
Hawk, S. T., Keijsers, L., Branje, S. J. T., van der Graaff, J., de Wied, M., \& Meeus, W. (2013). Examining the interpersonal reactivity index (IRI) among early and late adolescents and their mothers. Journal of Personality Assessment, 95, 96-106. doi:10.1080/00223891.201.696080

Hodge, K., \& Lonsdale, C. (2011). Prosocial and antisocial behavior in sport: The role of coaching style autonomous vs. controlled motivation, and moral disengagement. Journal of Sport \& Exercise Psychology, 33, 527-547. doi:10.1123/jsep.33.4.527

Holt, N., Neelym K. C., Slater, L. G., Camiré, M., Cóte, J., Fraser-Thomas, J.,...Tamminen, A. (2016). A grounded theory of positive youth development through sport based on results from a qualitative meta-study. International Review of Sport \& Exercise Psychology, 10, 1-49.

Kavussanu, M. (2006). Motivational predictors of prosocial and antisocial behaviour in football. Journal of Sports Sciences, 24, 575-588. doi:10.1080.02640410500190825

Kavussanu, M. (2008). Moral behaviour in sport: a critical review of the literature. International Review of Sport and Exercise Psychology, 1, 124-138. doi:10.1080/17509840802277417

Kavussanu, M \& Boardley, I, D (2009). The prosocial and antisocial behavior in sport scale. Journal of Sport \& Exercise Psychology, 31, 97-117. doi:10.1123/jsep.31.1.97

Kavussanu, M., \& Spray, C. M. (2006). Contextual influences on moral functioning of male youth footballers. The Sport Psychologist, 20, 1-23. doi:10.1123/tsp.20.1.1

Kavussanu, M., Stamp, R., Slade, G., \& Ring, C. (2009). Observed prosocial and antisocial behaviors in male and female soccer players. Journal of Applied Sport Psychology, 21, S62S76. doi:10.1080/10413200802624292

Kavussanu, M., \& Stanger, N. (2017). Moral behavior in sport. Current Opinion in Psychology, 16, 185-192. doi:10.1016.jcopsyc.2017.05.010

Kavussanu, M., Stanger, N., \& Boardley, I. D. (2013). The prosocial and antisocial behaviour in sport scale: Further evidence for construct validity and reliability. Journal of Sports Sciences, 31, 1208-221. doi:10.1080/02640414.2013.775473 
Kline, R.B. (2016). Principles and practice of structural equation modeling. (4 ${ }^{\text {th }}$ Ed.). New York: The Guilford Press.

Marsh, H. W., Hau, K. T., \& Wen, Z. L. (2004). In search of golden rules: comment on hypothesis testing approaches to setting cutoff values for fit indexes and dangers of overgeneralising $\mathrm{Hu} \&$ Bentler (1999) findings. Structural Equation Modeling, 11, 320-341. doi:10.1207/s15328007sem1103_2

Overgaauw, S., Rieffe, C., Broekhof, E., Crone, E. A., \& Güroğlu, B. (2017). Assessing empathy across childhood and adolescence: Validation of the empathy questionnaire for children and adolescents (EmQue-CA). Frontiers in Psychology, 8, 870. doi:10.3389/fpsyg.2017.00870

Papaionnou, A., Marsh, H. W., \& Theodorakis, Y. (2004). A multilevel approach to motivational climate in physical education ad sport settings: An individual or a group level construct? Journal of Sport \& Exercise Psychology, 26, 90-118. doi:10.1123/jsep.26.1.90

Pecukonis, E.V. (1990). A cognitive/affective empathy training program as a function of ego development in aggressive adolescent females. Adolescence, 25, 59-76.

Rutten, E. A., Deković, M., Stams, G. J. J., Schuengel, C., Koeksma, J. B., Biesta, G. J. J. (2008). On- and off-field antisocial and prosocial behavior in adolescent soccer players: a multilevel study. Journal of Adolescence, 31, 371-387. doi:10.1016/j.adolescence.2007.06.007

Sage, L., \& Kavussanu, M. (2008). Goal orientations, motivational climate, and prosocial and antisocial behaviour in youth football: exploring their temporal stability and reciprocal relationships. Journal of Sports Sciences, 26, 717-732. doi:10.1080/0264041070176916

Sage, L., Kavussanu, M., \& Duda, J. (2006). Goal orientations and moral identity as predictors of prosocial and antisocial functioning in male association football players. Journal of Sports Sciences, 24, 455-466. doi:10.1080/02640410500244531

Shields, D. L., Funk, C. D., Bredemeier, B. L. (2015). Predictors of moral disengagement in sport. Journal of Sport \& Exercise Psychology, 37, 646-658. doi:10.1123/jsep.2015-0110 
SOCIAL VARIABLES, PERSPECTIVE TAKING AND MORAL BEHAVIOR

Shrout, P. E., \& Bolger, N. (2002). Mediation in experimental and nonexperimental studies: New procedures and recommendations. Psychological Methods, 7, 422-445.

Shumaker, S. A., Brownell, A. (1984). Toward a theory of social support: Closing conceptual gaps. Journal of Social Issues, 40, 11-36. doi:10.1111/j.1540-4560.1984.tb01105.x

Smith, R. E., Cumming, S. P., \& Smoll, F. L. (2008). Development and validation of the motivational climate scale for youth sports. Journal of Applied Sport Psychology, 20, 116-136. doi:10.1080/10413200701790558

Stanger, N., Kavussanu, M., Boardley, I. D., \& Ring, C. (2013). The influence of moral disengagement and negative emotion on antisocial sport behavior. Sport, Exercise \& Performance Psychology, 2, 117-129. doi:10.1037/a0030585

Stanger, N., Kavussanu, M., McIntyre, D., \& Ring, C. (2016). Empathy inhibits aggression in competitions: The role of provocation, emotion and gender. Journal of Sport \& Exercise Psychology, 38, 4-14. doi:10.1123/jsep.2014-0332

Stanger, N., Kavussanu, M., \& Ring, C. (2012). Put yourself in their boots: Effects of empathy on emotion and aggression. Journal of Sport \& Exercise Psychology, 34, $208-222$. doi:10.1123/jsep.34.2.208

Stanger, N, Kavussanu, M., \& Ring, C. (2017). Gender moderates the relationship between empathy and aggressiveness: the mediating role of anger. Journal of Applied Sport Psychology, 29, 44-58. doi:10.1080/10413200.2016.1196764

Traclet, A., Romand, P., Moret, O., \& Kavussanu, M. (2011). Antisocial behavior in soccer: A qualitative study of moral disengagement. International Journal of Sport \& Exercise Psychology, 9, 143-155. doi:10.1080/1612197X.2011.567105

Weiss, M. (2008). "Field of dreams:" sport as a context for youth development. Research Quarterly for Exercise \& Sport, 79, 434-449. doi:10.1080/02701367.2008.10599510 
SOCIAL VARIABLES, PERSPECTIVE TAKING AND MORAL BEHAVIOR

Table 1

Correlations, descriptive statistics and alpha coefficients $(N=270)$.

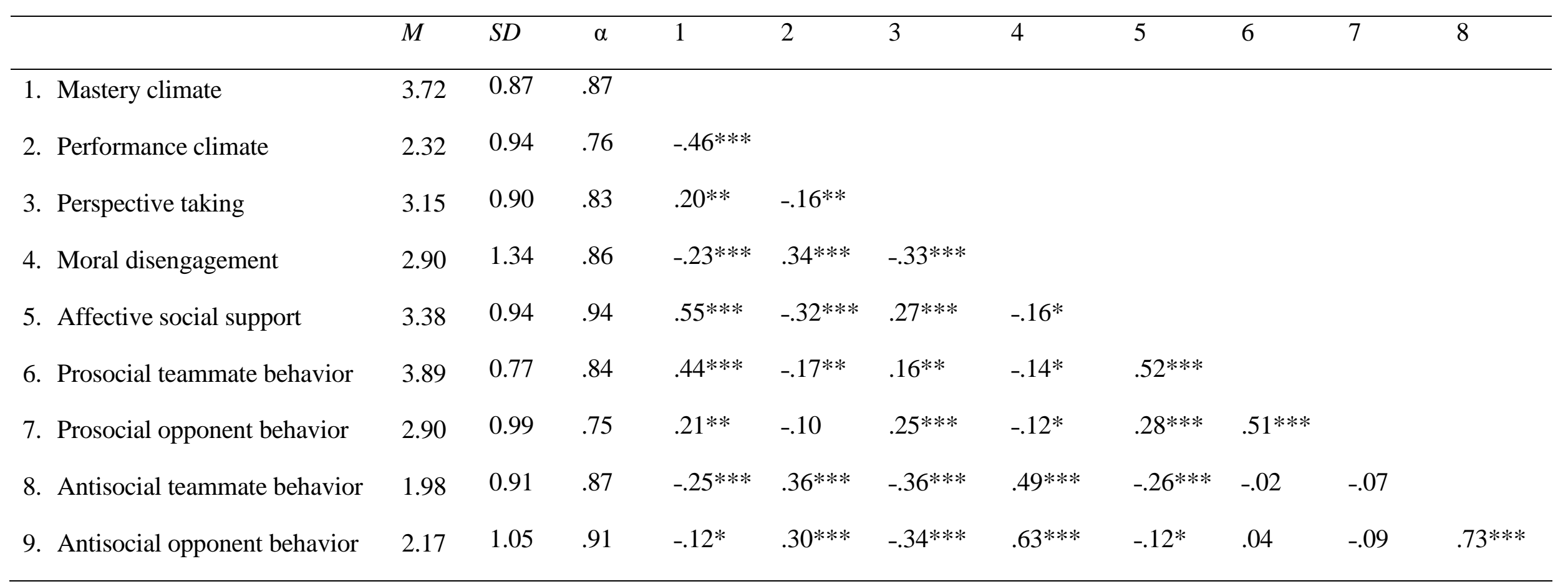

Note. Affective social support refers to the combined scale for emotional and esteem support. Motivational climate, perspective taking, social support as well as prosocial and antisocial behaviors were measured on scales from 1 to 5 . Moral disengagement was measured on a 1 to 7 scale. * $p<.05, * * p<.01, * * * p<.001$. 
SOCIAL VARIABLES, PERSPECTIVE TAKING AND MORAL BEHAVIOR

Table 2. Model fit indices

\begin{tabular}{|c|c|c|c|c|c|c|c|}
\hline Model & $d f$ & $\mathrm{~S}-\mathrm{B} \chi^{2}$ & $\chi^{2 / / \mathrm{df}}$ & CFI & TLI & RMSEA & SRMR \\
\hline Hypothesized & 1046 & 1471.33 & 1.41 & .936 & .931 & .039 & .062 \\
\hline Final (revised parsimonious model) & 1050 & 1473.15 & 1.40 & .937 & .932 & .039 & .062 \\
\hline Perspective taking as exogenous variable & 1049 & 1479.13 & 1.41 & .936 & .931 & .039 & .064 \\
\hline Saturated & 1083 & 1524.68 & 1.41 & .935 & .929 & .039 & .059 \\
\hline \multicolumn{8}{|l|}{ Model fit when controlling for age } \\
\hline Hypothesized & 1085 & 1556.35 & 1.43 & .931 & .925 & .040 & .061 \\
\hline Final (revised parsimonious model) & 1089 & 1587.68 & 1.43 & .931 & .926 & .040 & .061 \\
\hline Perspective taking as exogenous variable & 1088 & 1564.40 & 1.44 & .930 & .924 & .040 & .063 \\
\hline Saturated & 1123 & 1612.17 & 1.44 & .930 & .923 & .040 & .059 \\
\hline
\end{tabular}

Note: We reported the CFI, TLI, RMSEA, and SRMR to 3 decimal points to enable more direct comparisons between fit indices for each specified model. 
Table 3. Indirect effects for the revised hypothesized model.

Path Indirect effect $\quad 95 \%$ CIs

$\mathrm{MC} \rightarrow$ Social Support $\rightarrow$ Perspect. Taking $\rightarrow$ PT Behavior

$\begin{array}{ll}.27(.07)^{* * *} & .14 \text { to } .42 \\ .19(.05)^{* * *} & .10 \text { to } .29 \\ .18(.07)^{* *} & .05 \text { to } .31 \\ .07(.03)^{* *} & .03 \text { to } .14 \\ -.07(.02)^{* * *} & -.13 \text { to }-.04 \\ -.12(.04)^{* * *} & -.20 \text { to }-.06 \\ -.07(.02) * * * & -.13 \text { to }-.03 \\ -.11(.03)^{* * *} & -.19 \text { to }-.05 \\ -.17(.04)^{* * *} & -.27 \text { to }-.10 \\ -.07(.02)^{* * *} & -.13 \text { to }-.05 \\ -.11(.03)^{* * *} & -.19 \text { to }-.05 \\ -.26(.05)^{* * *} & -.37 \text { to }-.16 \\ .12(.04)^{* * *} & .06 \text { to } .20 \\ .18(.05)^{* *} & .09 \text { to } .27\end{array}$

$\mathrm{MC} \rightarrow$ Social Support $\rightarrow$ Perspect. Taking

$\mathrm{MC} \rightarrow$ Social Support $\rightarrow$ Perspect. Taking $\rightarrow$ PO Behavior

Social Support $\rightarrow$ Perspect. Taking $\rightarrow$ PO Behavior

$\mathrm{MC} \rightarrow$ Social Support $\rightarrow$ Perspect. Taking $\rightarrow$ MD

Social Support $\rightarrow$ Perspect. Taking $\rightarrow$ MD

$\mathrm{MC} \rightarrow$ Social Support $\rightarrow$ Perspect. Taking $\rightarrow$ MD $\rightarrow$ AT Behavior

Social Support $\rightarrow$ Perspect. Taking $\rightarrow$ MD $\rightarrow$ AT Behavior

Perspect. Taking $\rightarrow \mathrm{MD} \rightarrow$ AT Behavior

$\mathrm{MC} \rightarrow$ Social Support $\rightarrow$ Perspect. Taking $\mathrm{MD} \rightarrow$ AO Behavior

Social Support $\rightarrow$ Perspect. Taking $\rightarrow \mathrm{MD} \rightarrow$ AO Behavior

Perspect. Taking $\rightarrow \mathrm{MD} \rightarrow$ AO Behavior

$\mathrm{PC} \rightarrow$ Moral Dis. $\rightarrow$ AT Behavior

PC $\rightarrow$ Moral Dis. $\rightarrow$ AO Behavior

Note: Standardized coefficients are presented with standard errors in parentheses. Social support refers to a combined scale for emotional and esteem support (labelled affective social support). MC = Mastery Climate; Perspect. Taking $=$ Perspective Taking; PT Behavior $=$ Prosocial Teammate Behavior; AT Behavior = Antisocial Teammate Behavior; $\mathrm{MD}=$ Moral Disengagement; AO Behavior $=$ Antisocial Opponent Behavior, $\mathrm{PC}=$ Performance Climate, $* p<.05, * * p<.01, * * * p$ $<.001$. 


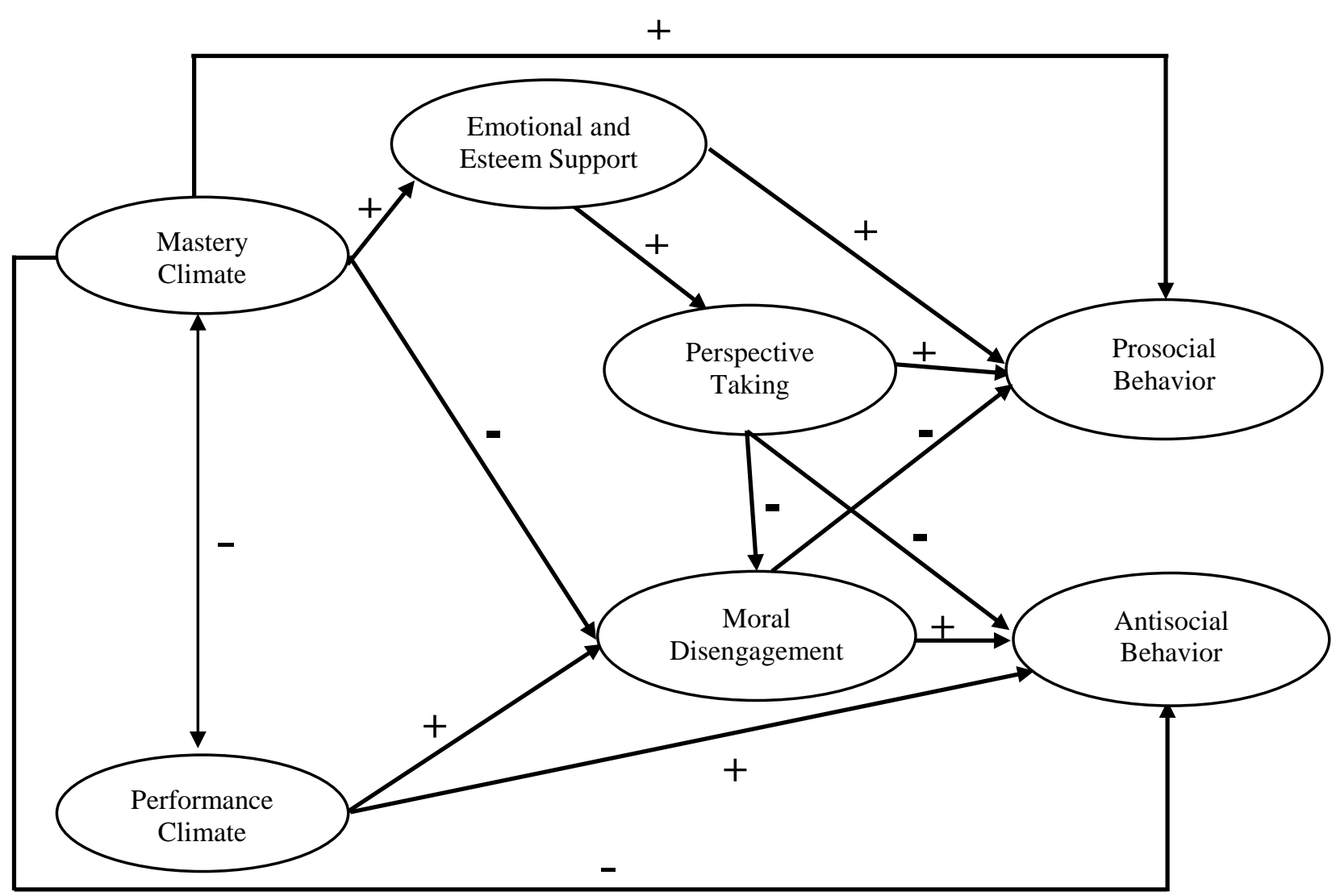

Figure 1. Hypothesized conceptual model. Prosocial behavior and antisocial behavior denotes to prosocial and antisocial behavior towards both teammates and opponents. 


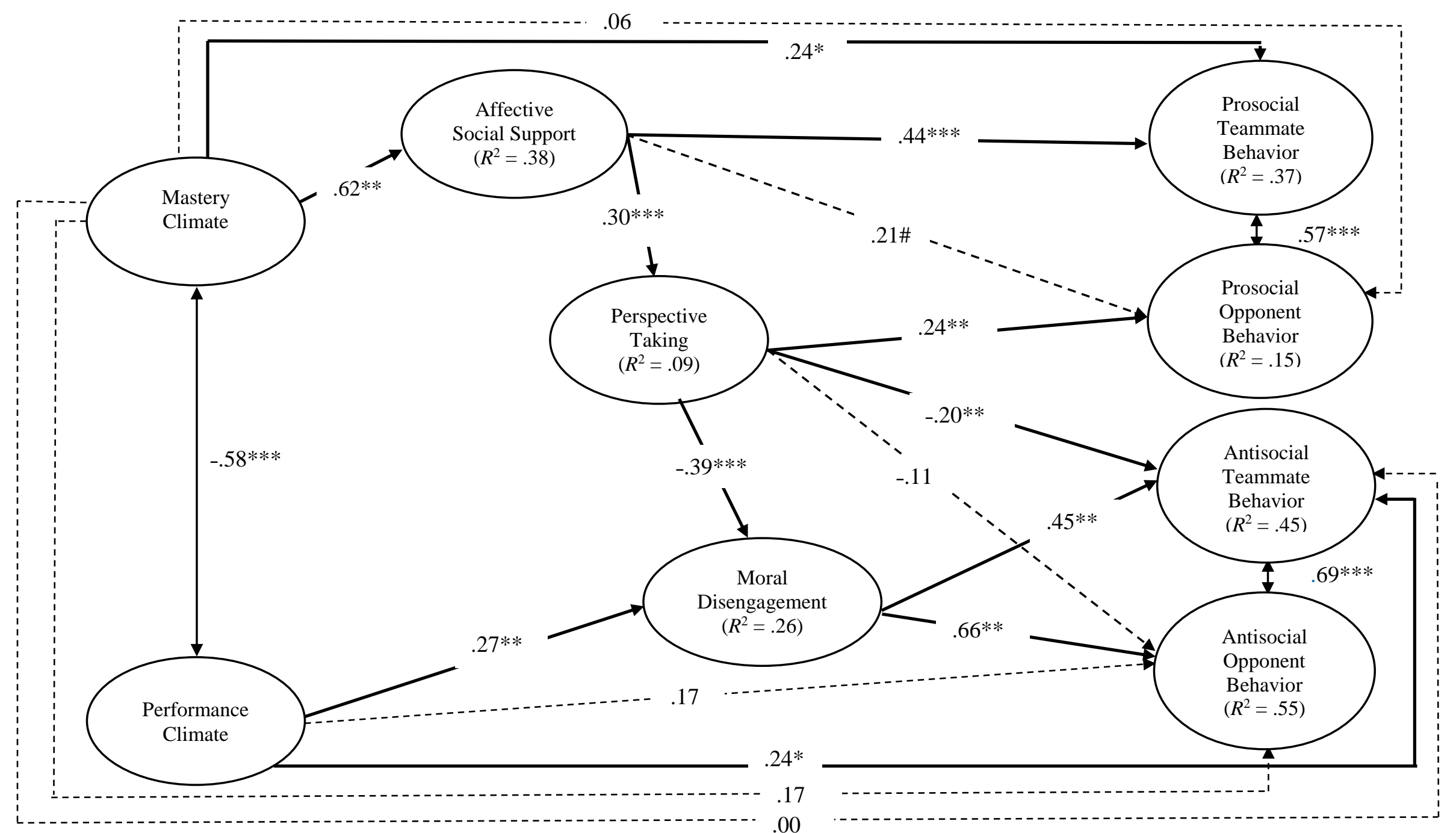

Figure 2. Structural equation modelling results for the final model. Standardized coefficients are reported based on bootstrap analysis; full lines represent significant effects and dashed lines represent effects that were not significant in the model. \#<.06, $* p<.05, * * p<.01, * * * p<.001$. 